\title{
A Novel Pre-Class Learning Content Approach for the Implementation of Flipped Classrooms
}

\author{
Soly Mathew Biju ${ }^{1}$, Ayodeji Olalekan Salau², Joy Nnenna Eneh ${ }^{3}$ \\ Vincent Egoigwe Sochima ${ }^{4}$, Izuchukwu ThankGod Ozue ${ }^{5}$ \\ Faculty of Engineering and Information Sciences University of Wollongong, Dubai ${ }^{1}$ \\ Department of Electrical/Electronics and Computer Engineering, Afe Babalola University, Ado-Ekiti, Nigeria ${ }^{2}$ \\ Department of Electronic Engineering, University of Nigeria, Nsukka, Nigeria ${ }^{3}$ \\ Department of Mechatronic Engineering, University of Nigeria, Nsukka, Nigeria, 5
}

\begin{abstract}
The nascent recognition of computing in curriculum across countries is also accompanied by several pedagogic inefficiencies especially concerning insufficient time available for teacher-student interaction. In this paper, a flipped classroom concept was identified as an effective approach to teaching students at various levels in the academia including Higher Education. Preparing the pre-class content and considering the format used to deliver it has not gained much consideration. There are several ways in which this content could be provided to students to prepare them before an in-class activity where a flipped-classroom approach can be implemented. The present study analyzed the success of the flipped classroom concept based on a comparative analysis of the two types of flipped classroom pre-class content delivery methods: online videos and online PowerPoint slides. Evaluation was performed using paired T-test. The results show that the two approaches have significantly different means and huge differences between them. The students preferred online videos to online PowerPoint (ppt) methods underlining the importance of the proposed flipped classroom approach.
\end{abstract}

Keywords-Flipped classroom; active learning; online videos; student-centered approach; increased interaction; pre-class content

\section{INTRODUCTION}

In recent times, new approaches are being adopted to enhance students learning and better improve on the studentteacher class interaction. Amongst the several approaches used is the flipped-classroom method which has shown promising results $[1,2]$.

\section{A. Pedagogical Loopholes in Infusing Skill Development among Computer Science Students}

Students with a Higher Education degree are expected to be equipped with skills related to creativity, problem-solving, analytical skills, critical thinking, multi-tasking, and resilience. The student must learn to work independently as well as in groups. In this context, the education system poses certain inefficiencies concerning its effective transmission among students. Inefficiencies of institutions in the form of limited time to practice, as well as limited interaction with faculty prevails. Moreover, there exist poor learning methods for students, especially the use of the traditional methods of teaching, and in addition, insufficient teaching approaches [3, 4]. Low self-efficacy, lack of motivation to learn courses, and lack of factors which identify loopholes in the system to infuse skills among students [5].

\section{B. Importance of Interactive Classroom in Class Activities: Emphasis on Flipped Classroom Approach}

A flipped classroom concept represents a transition from a teacher-centered approach to a student-centered approach whereby students have access to theoretical content via online videos, presentations, learning management systems before attending the classroom session. This encourages students to build an understanding of the concept, take notes, prepare questions so that the classroom session is turned into a hub of learning and every student is engaged enthusiastically [6]. For teachers, the flipped classroom helps in using their time more effectively to help weaker students understand and implement the taught concepts better. Steps followed by instructors and students in a typical flipped classroom session are clearly shown in Fig. 1(a) and (b), respectively.

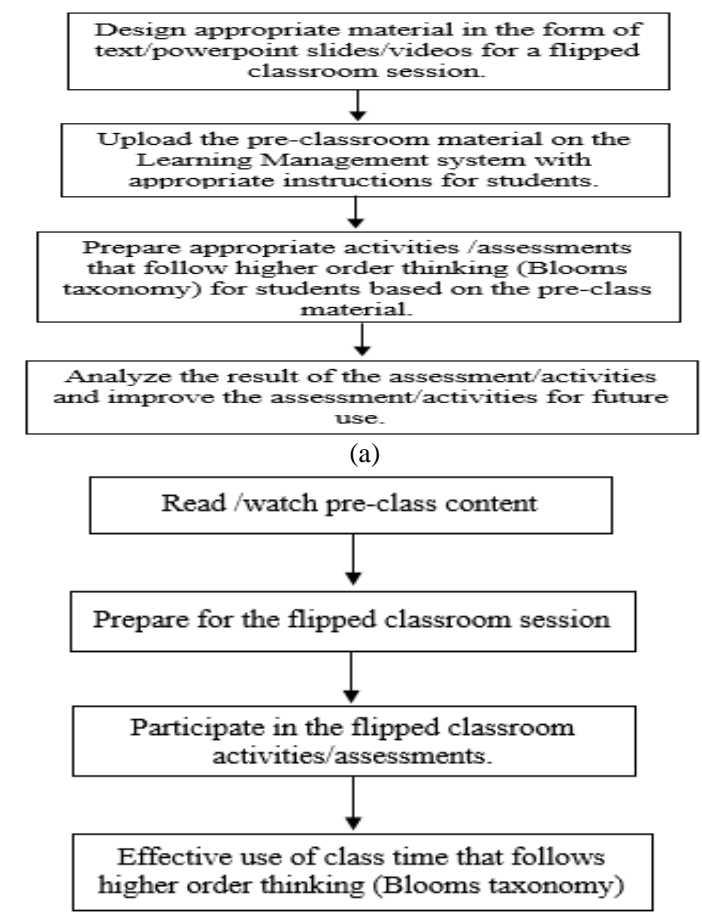

(b)

Fig. 1. Steps followed by Students in Flipped Classroom Implementation. 
The interactive classroom approach using the flipped classroom method can be a useful approach in enhancing the teacher-student relationship [7]. A number of research papers have reported that the flipped classroom develops a positive attitude in students and gives a better performance in taught courses in comparison with the traditional classroom teaching approaches [8-10]. Though a lot of research have been done on how to develop effective in-class activities and focus on student-centered learning [11-13], not much has been done in considering the quality of out of class content provided to students.

A quantitative study conducted in [14] found that student achievement was higher in the case of a flipped-classroom approach in comparison with traditional approaches. Though in-class activities should focus on active learning both [15] and [16] found that a flipped classroom was more effective in teaching concepts and had a positive impact on learning and student motivation.

However, authors in [17] and [18] have found that there were very little or no significant results in replacing the traditional teaching approach with the flipped classroom approach applied in introductory biology and nursing studies. These contradicting results lead to the conclusion that flipped classroom can be an effective strategy in improving the learning behavior of students. Most of these studies also indicated that the benefits of implementing a flippedclassroom approach highly depends on the readiness or ability of students to work independently and acquire self-regulatory skills to come prepared for the out of class tasks [19].

Porcaro et al. [20] indicated that most of the students (8993\%) completed a pre-class tasks when the pre-class content was in the form of video lectures. This may indicate how well prepared the students were, and may also indicate the other factors such as how different format of the out of class content influences student's readiness in preparation for a flipped classroom session.

Most of the pre-class content is in the form of pre-recorded lectures or screencast [21]. Other methods of pre-class content dissemination include readable contents, Blogs, and Google Docs [22].

The subsequent sections of this paper are organized into the following sections: In Section II we discuss in detail the need for the study, while in Section III we present our proposed research methodology. In Section IV we give the results and findings, while in Section $\mathrm{V}$ we discuss the results. In Section VI the paper is concluded and therein we indicate opportunities for future research works.

\section{NEED FOR THE STUDY}

In light of the above-mentioned facts which include insufficient class time highlights the need for a technologybased interactive method such as flipped classroom sessions. These are constructed and organized by teachers in the form of videos, presentations or pdf reading material uploaded in various leaning management systems. It is thus crucial that teachers prepare the content carefully as it helps in building the students taking the course. It is a common phenomenon for teachers to take an active interactive session rather than a session executing an entire topic within a class session. Hence, it is necessary to investigate various methods for designing pre-class materials for successful flip classroom implementation. Besides, the tools used in the flipped classroom concepts are well prepared and understandable to the students [23]. The pre-class material design could be in the form of online PowerPoint (ppt) presentations, videos, learning management systems, etc. There is also the need to make a comparative analysis of the type of pre-class material that effectively helps the students.

We look at two formats in which pre-class content is made available to the students. First is reading text format or in the form of detailed ppt slides and video lectures.

\section{A. Text Material}

Textbook-style reading is usually used by lecturers to provide students with a short and straight to the point easy to understand low-level content in line with lower items in bloom's taxonomy. These are used at high school and university levels and are considered as an important element of the learning experience. When we compare textbook reading to video materials, we can state that it is easy to search and read through the relevant content multiple times with ease. A study in [24] showed that textbooks are often the main resource for the majority of the students. Though textbook reading materials are often used in traditional teaching style, when used in a flipped classroom environment, students are required to have read and understood the concepts to be able to apply it to the corresponding in-class activity. This is in contrast to a traditional teaching style where reading pre-class content is not enforced [25]. In a traditional teaching environment, many students do not bother to read the assignments [26, 27].

\section{B. Video Lectures}

Video lectures focus on two modes of information processing which are: visual and auditory. According to authors in [28] who used dual coding theory, the more sensory pathways that a student can use to interact with the material, the more likely the student will remember the content [29]. Yadav et al. [30] suggested that video may be a more powerful medium for cognitive and affective information processing compared to text reading alone.

In this paper, we used the two content learning strategies for out-of-classroom content learning in a flipped-classroom approach, while keeping the implementation of the in-class activities for future works.

- Central aim

The present study aims to analyze the role of flipped classroom concept and its tools implemented in higher education for developing skills among computer science students.

- Central question of the study

Is the benefit perceived by students in a flipped classroom approach based on the type of pre-class content design for a flip classroom approach? 
Is there a difference in the performance of the students studying with the pre-class content materials (online videos, online power points slides) in the context of higher education?

\section{RESEARCH Methodology}

This sections describes the method, strategy and organized processes performed in collecting and analyzing the required data for achieving the aim of the research study and solving the central research problem [31, 32]. For the present study, authors have employed a positivist paradigm which is objective and predictable in its approach. Besides, a descriptive and explanatory research method has been applied for analyzing the characteristics of the selected research topics whereby these methods were used to collect quantitative data for the same. Another part of the research methodology is a suitable research approach that guides the course of study. Authors have used the deductive research approach here. With this approach, a structured theory is formed in the initial phase of the study which deals with quantitative data collection [33]. Hence the study involved two different pre-class flipped instruction methods, namely, online video lectures versus online lecture material (text or PowerPoint (ppt) slides), and the result of these methods were evaluated with the students preferences and other associated parameters concerning higher education.

\section{A. Participants}

A survey was administered to students. The survey was majorly administered among 160 students pursuing higher education. As for the respondent's profile, the major targeted population included students of computer science subjects in higher education. Also, the sampled population was obtained through the method of non-random convenience sampling method, i.e. the samples were selected as per the convenience of the researcher.

\section{B. Measurement Instruments and Measures}

The measuring instruments were survey questionnaires (close-ended and structured), which had a demographic and inferential part which helped in assessing the impact of flipped classroom sessions. For conducting the survey, prior permission was taken from authorities of the concerned institutes, faculty, and students. The inferential section comprised of scores of students undertaking flipped classroom material. Around 190 undergraduate students were approached as per the convenience of the authors in approaching them for the required survey and 160 of them reverted. Two different pre-class learning materials were used- online video lectures and online lecture material. The results of these methods were compared and evaluated based on student's preferences and other associated parameters. The topics were from a problem solving subject taught to students in their first year of Computer Science. The topics were introductions to different sorting algorithms. In the case of video-based pre-class learning materials, a video was uploaded to explain to students the concept of selection sorting approach [34, 35]. In the case of reading material based flipped classrooms, the students were required to read and go through the PowerPoint slides to understand the algorithm for bubble sort.

\section{Procedure of Data Analysis}

Data was collected based on scores of students in common assessments with the pre-class content students used to understand and study the concept covered in a flipped classroom teaching. A t-test Statistical Package for Social Science (SPSS) v21 was used to evaluate the significance of the results.

The assessments were conducted in the class after a quick recap of what was covered in the pre-class material for both the types of material power point/text and video lecture. Assessments conducted were at the sample level of complexity. All questions were carefully drafted to avoid any type of bias. Questions ranged from multiple questions to problem-solving using the concepts learned. Scores obtained by the students in all three assessment were used to evaluate the differences between using two types of materials.

\section{RESUlTS AND FINDINGS}

The results presented in Fig. 2 revealed that only 11.54\% of the students were not aware of the flipped classroom sessions and preferred online lecture notes to online videos. Also out of the remaining students who knew about the concept, $59.62 \%$ of them preferred online videos to online lecture notes.

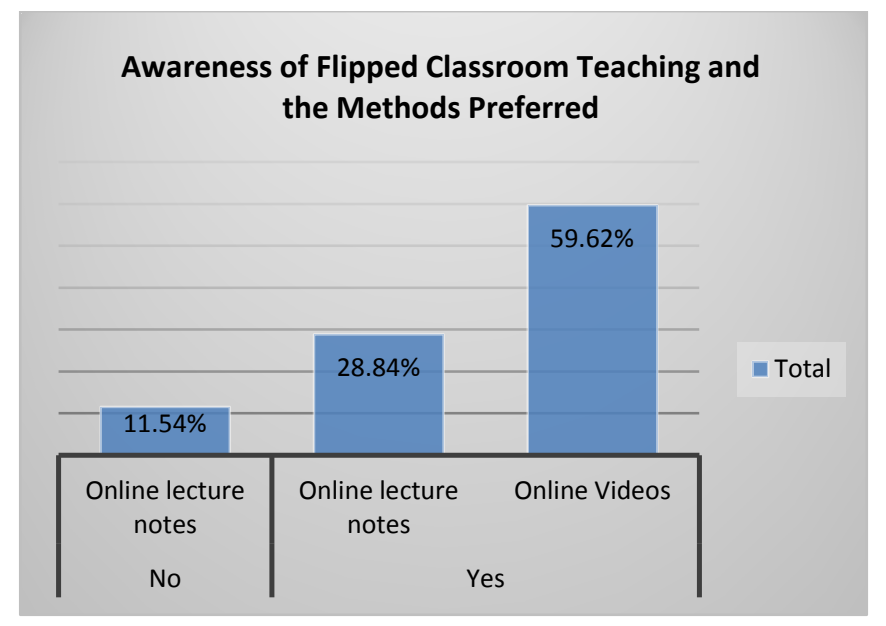

Fig. 2. Awareness of Flipped Classroom Teaching and the Methods Preferred.

Given the general and background information of the respondents, the next section took into account the inferential analysis including hypothesis testing for presented objective of the study thereby presenting several insights and implications of the same.

\section{A. Inferential Analysis}

To achieve the objective of study which aimed to provide a comparative analysis of the two types of pre-class content methods to support flipped-classroom approach: online videos and online lecture (reading) materials in the form of text or PowerPoint slides, the authors have used the t-Test Paired Two Sample for Mean difference determination. This method helps in making a comparison between two dissimilar approaches of measurement or two diverse treatments concerning a common subject [36]. In this section, a 
comparison was made between the two types of pre-class content design to support a flipped classroom concept. Furthermore, this method was used to test the means of a population between two groups such that the null hypothesis states that the means of two populations are equal. However, the variances of both populations are not necessarily equal.

Therefore:

$H_{0} 1$ means there is no significant difference in the mean of the video preferring group and PowerPoint slides preferring group,

while $H_{A} 1$ means there is significant difference in the mean of the video preferring group and PowerPoint slides preferring group.

Table I shows that the p-value is very close to zero and is thus less than 0.5. Therefore the null hypothesis is rejected. This means the mean of the two flipped classroom teaching methods are not the same. Also, $\mathrm{P}(\mathrm{T}<=\mathrm{t})$ two tail (3.78146E19) represents the probability that the absolute value of the tStatistic (14.32850425) is larger in absolute value than the critical t-value (2.009575199) as well as 0 . Thus, it can be stated that according to the t-criterion that the claim for alternative hypothesis is accepted $\left(|t| \geq t_{\alpha / 2 ; v}\right)$.

Furthermore, Table II reveals that the students enjoyed working with online video sessions than using reading materials and a perceived great confidence level in attending the concerned sessions was attained.

TABLE I. T-Test RESUlts of THE TwO FLIPPED ClASSROOM APPROACHES

t-Test: Paired Two Sample for Means

\begin{tabular}{|l|l|l|}
\hline & Video & PPT slides \\
\hline Mean & 69.13333333 & 48.01111111 \\
\hline Variance & 43.50793651 & 157.962837 \\
\hline Observations & 50 & 50 \\
\hline Pearson Correlation & 0.559799717 & \\
\hline Hypothesized Mean Difference & 0 & \\
Df & 49 & \\
t Stat & 14.32850425 & \\
P(T<=t) one-tail & $1.89073 \mathrm{E}-19$ & \\
t Critical one-tail & 1.676550893 & \\
P(T<=t) two-tail & $3.78146 \mathrm{E}-19$ & \\
t Critical two-tail & 2.009575199 & \\
& & \\
\hline
\end{tabular}

TABLE II. RESUlTS OF THE SURVEY

\begin{tabular}{|l|l|l|}
\hline & Video & $\begin{array}{l}\text { Reading Material } \\
(\mathrm{ppt})\end{array}$ \\
\hline $\begin{array}{l}\text { Enjoyed working on the requirement out of } \\
\text { class }\end{array}$ & 70 & 30 \\
\hline Engaged in interaction with others in class & 40 & 60 \\
\hline Required more effort to perform activity & 30 & 70 \\
\hline Required more time to follow the concept & 40 & 60 \\
\hline Enjoyed the class activity & 40 & 60 \\
\hline $\begin{array}{l}\text { Confidence level was high after flipped } \\
\text { session and before attending the class }\end{array}$ & 70 & 30 \\
\hline
\end{tabular}

\section{DisCUSSION OF RESUlts}

\section{A. Discussion of findings and Answers to Questions Posed}

In this section, the role of flipped classroom concept was analyzed and its tools in higher education for developing skills along with a comparative analysis of the two types of flipped classroom approaches: online videos and online lecture (reading) material were performed. From the results in Table I, it can be observed that the two approaches have significantly different means and huge differences between them. Online videos sessions was preferred by most of the students over online PowerPoint as a pre-class learning material to support the flipped-classroom approach. It was also observed that flipped classroom sessions were effective and played an instrumental role in the life of students in terms of developing related skills like problem-solving. The students were more confident and active with the proposed approach in contrast with the traditional way of teaching whereby students were hesitant to ask any query. Moreover, the students developed a critical understanding of the topics and were highly motivated in interacting with their faculty. This helped to develop better relationships and interaction among them. Furthermore, the overall perception and attitudes of students was changed, thus leading to increased student performance.

\section{B. Study Implications}

The present study is useful and effective for both the recent generation of students as well as teachers since they can investigate their perceptions on the concept of well-designed pre-class learning materials using the correct methods to support the flipped classroom concept. Besides, the study will pave the way for other researchers who are interested in this nascent establishment of teaching within the curriculum which in turn needs huge discussions with respect to updating the content of the curriculum. The study also helped in analyzing the effects and views of students with regards to the concept of flipped classroom thereby highlighting the role of integrating technology in educational systems along with their critical evaluation. Therefore, this study is crucial as an important medium of knowledge retention among students. It also highlights that the success of a flipped-classroom approach mainly depends on the type of pre-class content provided to the students.

For this study, we have assumed that the content and the quality of the content were up to the expected standards. The findings of this paper are in contrast with authors in [37] who claim that there is no difference between video lectures and text readings. In addition, this study also focused on the importance of using the correct format or medium to design the pre-class content which guarantees that a maximum number of students actively participate leading to a successful flipped classroom session.

\section{CONCLUSION AND FUtURE RESEARCH}

This study presented a novel learning approach to the concept of flipped classroom. Two flipped classroom methods were analyzed and evaluated. The results show that the online videos method of teaching was mostly preferred to other methods. The study showed that the success of flipped classroom depends on how prepared students are to work and 
study with minimum guidance outside the class. This research shows that students clearly prefer video lectures or text or ppt slides lectures. The performance of the students who were assigned to view videos as pre-class content shows a significant improvement in performance as compared to students who used text or ppt slides as their pre-class content.

Thus, future research will be conducted based on data obtained from students who attend a flipped-classroom session throughout the semester for various subjects in the university. Furthermore, in future works, we hope to use qualitative study methods such as interviews and focus groups for teachers and instructors to get an elaborate and specialized viewpoint of instructors for content design strategies that could be used to support flipped classroom approaches. Another limitation of the study is that it did not take into account other specific skills like critical thinking, creativity, resilience, analytical reasoning, etc. which could affect the performance of students. Therefore, we recommend that an analysis incorporating a wide level survey capturing these different skill set of students be conducted.

\section{REFERENCES}

[1] S. M. Biju, Students perception on the benefits of blended learning in Higher Education: Flipped classroom approach, 2nd International Conference on Global Education and E -Learning "Digital Literacies and Education: Spaces, Mobilities and Practices, (2018), 12-13.

[2] M. Bower, L. N. Wood, J. W. M. Lai, C. Howe, and R. Lister, Improving the computational thinking pedagogical capabilities of school teachers. Australian Journal of Teacher Education, 42(3) (2017), 53-72. DOI: 10.14221/ajte.2017v42n3.4.

[3] S. M. Biju, Difficulties in understanding object oriented programming concepts, in: K. Elleithy and T. Sobh (eds), Innovations and Advances in Computer, Information, Systems Sciences, and Engineering, Springers, Netherlands, (2013), 319-326.

[4] O. O. Fashade, B.O. Salu, A. O. Salau, A. G. Ojo, O. S. Ajala, Development of a VSAT based virtual e-learning system: (ARCSSTE-E as a case study), International Journal of Engineering Trends and Technology, 48(7) (2017), 398-403. DOI: 10.14445/22315381/IJETTV48P269.

[5] M. N. Ismail, N. A. Ngah, and I. N. Umar, Instructional strategy in the teaching of computer programming: A need assessment analyses, Turkish Online Journal of Educational Technology, 9(2) (2010), 125131.

[6] L. Drake, M. Kayser, and R. Jacobowitz, The flipped classroom. an approach to teaching and learning, A 2020 Vision for Public Education in Ulster County (2016). Retrieved from http://www.newpaltz.edu/ media/the-benjamin-center/P.Brief_2020Vision-Flipped classroom.pdf

[7] Cisco, The flipped classroom: empowering students to take charge of their learning, (2012) 1-9. Retrieved from http://www.cisco.com/web/ strategy/docs/education/flipped_classroom_whitepaper.pdf

[8] G. Bergstrom, Content vs. learning: an old dichotomy in science courses, Journal of Asynchronous Learning Networks, 15 (2011), 33-44.

[9] B. J. Phillips and F. Phillips, Sink or skim: textbook reading behaviors of introductory accounting students, Issues in Accounting Education, 22(1) (2007), 21-44.

[10] S. M. Biju, Best approach to teach advanced programming, International Journal of Education and Management Engineering (IJEME), 8(6) (2018), 37-45. DOI: 10.5815/ijeme.2018.06.04.

[11] A. Roehl, S. L. Reddy, and G. J. Shannon, The flipped classroom: an opportunity to engage millennial students through active learning, Journal of Family and Consumer Sciences, 105(2) (2013), 4449.

[12] P. Baepler, J. D. Walker, and M. Driessen, It's not about seat time: blending, flipping, and efficiency in active learning classrooms, Computers in Education, 78 (2014), 227-236.
[13] J. E. McLaughlin, M. Roth, D. M. Glatt, N. Gharkholonarehe, C. A. Davidson, L. M. Griffin, D. A. Esserman, and R. J. Mumper, The flipped classroom: a course redesign to foster learning and engagement in a health professions school, Academic Medicine, 89 (2014), 1-8.

[14] P. Schwarzenberg, J. Navon, M. Nussbaum, M. Pérez-Sanagustín, and D. Caballero, Learning experience assessment of flipped courses, Journal of Computing in Higher Education, (2017), 1-22.

[15] V. Betihavas, H. Bridgman, R. Kornhaber, and M. Cross, The evidence for 'flipping out': a systematic review of the flipped classroom in nursing education, Nurse Education Today, 38 (2016), 15-21.

[16] Z. Zainuddin and S. H. Halili, Flipped classroom research and trends from different fields of study, International Review of Research in Open and Distributed Learning, 17(3) (2016), 314-340.

[17] S. A. Harrington, M. V. Bosch, N. Schoofs, C. Beel-Bates, and K. Anderson, Quantitative outcomes for nursing students in a flipped classroom, Nursing Education Perspectives, 36(3) (2015), 179-181.

[18] J. L. Jensen, T. A. Kummer, and P. D. M. Godoy, Improvements from a flipped classroom may simply be the fruits of active learning, CBE Life Sci Educ. 14(1) (2015). DOI: 10.1187/cbe.14-08-0129.

[19] S. R. Sletten, Investigating flipped learning: student self-regulated learning, perceptions, and achievement in an introductory biology course, Journal of Science Education and Technology, 26(3) (2017), 347-358.

[20] P. A. Porcaro, D. E. Jackson, P. M. McLaughlin, and C. J. O’Malley, Curriculum design of a flipped classroom to enhance haematology learning, Journal of Science Education and Technology, 25(3) (2016), 345-357.

[21] M. Estrada, G. Vera, R. Ruiz, and A. Arrebola, Flipped classroom to improve university student centered learning and academic performance, Social Sciences, 8(11) (2019), 315-321. DOI: 10.3390/socsci8110315.

[22] J. L. Jensen, E. A. Holt, J. B. Sowards, Investigating strategies for preclass content learning in a flipped classroom. J Sci Educ Technol, 27, 523-535 (2018). DOI: 10.1007/s10956-018-9740-6.

[23] Y. Zhao and A. Ho, Evaluating the flipped classroom in an undergraduate history course, (2014), 1-48. http://harvardx.harvard.edu/ files/harvardx/files/evaluating_the_flipped_classroom_zhao_and_ho.pdf

[24] D. Besser, G. Stone, and L. Nan, Textbooks and teaching: a lesson from students, Journalism \& Mass Communication Educator, 53(4) (1999), 417.

[25] W. He, A. Holton, G. Farkas, and M. Warschauer, The effects of flipped instruction on out-of-class study time, exam performance, and student perceptions, Learning and Instruction, 45 (2016), 61-71.

[26] J. F. Sikorski, K. Rich, B. K. Saville, W. Buskist, O. Drogan, and S. F. Davis, Student use of introductory texts: comparative survey findings from two universities, Teaching of Psychology, 29(4) (2002), 312-313.

[27] E. Han and K. C. Klein, Pre-class learning methods for flipped classrooms, Am J Pharm Educ. 83(1): 6922, (2019). DOI: 10.5688/ajpe6922.

[28] A. Paivio, Mental representations: a dual coding approach, New York: Oxford University Press (1990).

[29] J. M. Clark, and A. Paivio, Dual coding theory and education, Educational Psychology Review, 3(3) (1991), 149210. DOI: $10.1007 / \mathrm{BF} 01320076$.

[30] A. Yadav, M. M. Phillips, M. A. Lundeberg, M. J. Koehler, K. Hilden, and K. H. Dirkin, If a picture is worth a thousand words is video worth a million? Differences in affective and cognitive processing of video and text cases. Journal of Computing in Higher Education, 23(1) (2011), 1537.

[31] E. Cabi, The impact of the flipped classroom model on students' academic achievement, International Review of Research in Open and Distance Learning, 19(3) (2018). DOI: 10.19173/irrodl.v19i3.3482.

[32] H. Al-Samarraie, A. Shamsuddin, and A.I. Alzahrani, A flipped classroom model in higher education: a review of the evidence across disciplines, Education Tech Research Dev 68, 1017-1051 (2020). DOI: 10.1007/s11423-019-09718-8.

[33] A. Burney, Inductive \& deductive research approach (2008). DOI: 10.13140/RG.2.2.31603.58406. 
[34] A. A. Adamu, D. Wang, A. O. Salau, and O. Ajayi, An integrated IoT system pathway for smart cities, International Journal on Emerging Technologies, 11(1) (2020), 1-9.

[35] A. O. Salau, I. Oluwafemi, K.F. Faleye, and S. Jain, Audio compression using a modified discrete cosine transform with temporal auditory masking, 5th IEEE International Conference on Signal Processing and Communication (ICSC), Noida, India, (2019) 135-142. DOI: 10.1109/ICSC45622.2019.8938213.
[36] R. Sheer, Statistics: 1.1 Paired t-tests, (2004), 1-3. Retrieved from http://www.statstutor.ac.uk/resources/uploaded/paired-t-test.pdf.

[37] M. Moravec, A. Williams, N. Aguilar-Roca, \& D. K. O’Dowd, Learn before lecture: a strategy that improves learning outcomes in a large introductory biology class, CBE Life Sciences Education, 9(4) (2010), 473-481. 